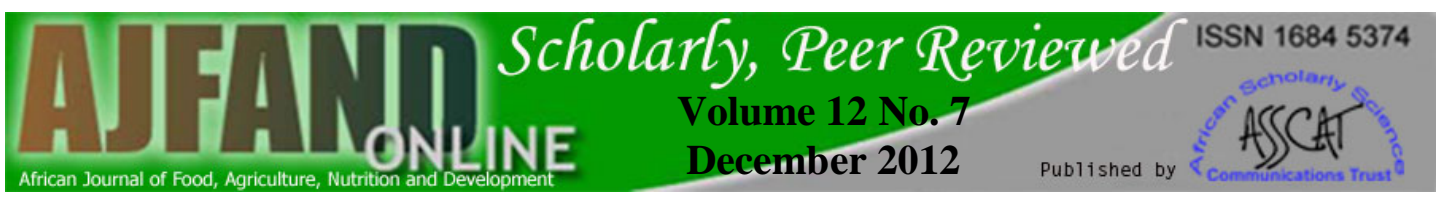

\title{
EFFECT OF NUTRITION EDUCATION ON KNOWLEDGE OF NUTRITION IN RELATION TO PREVENTION OF STOMACH CANCER AMONG UNDERGRADUATES IN SOUTH-WEST, NIGERIA
}

$$
\text { Anetor GO*1, BO Ogundele }{ }^{2} \text { and OE Oyewole }{ }^{3}
$$

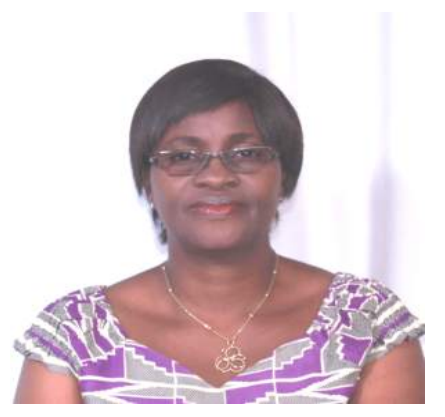

\section{Gloria Anetor}

*Corresponding author email: yahuanet@yahoo.com

${ }^{1}$ Department of Clinical Nursing, University College Hospital, Ibadan; P.O.Box 21981 University of Ibadan, Nigeria

${ }^{2}$ Department of Human Kinetics and Health Education, Faculty of Education, University of Ibadan, Nigeria

${ }^{3}$ Department of Health Promotion and Education, College of Medicine, University of Ibadan, Nigeria 


\section{ABSTRACT}

Stomach cancer is one of the common cancers worldwide including developing countries and is identified as one of the most lethal among the diet related cancers. In Nigeria, there is paucity of data and information about the prevalence of stomach cancer and without doubt this disease is on the increase. Youth engage in the consumption of western diets which have been identified in the literature as one factor that is closely associated with cancers. This shift to western diets by most youth may be due to lack of nutritional knowledge on the health consequences of their eating habits. In years to come, there may be an increase in the incidence of diet-related cancers and other chronic diseases if nutrition education is not put in place especially among the youth. Not many studies in Nigeria have focussed on nutrition education of the youth in relation to the prevention of chronic diseases; prominent among which is stomach cancer. This study is aimed at providing nutrition related education to university undergraduates in order to create awareness about nutrition with a view to preventing a rise in the incidence of stomach cancer and other chronic diseases. A quasi-experimental design was used for this study. Multi-stage sampling was used to select 436 male and female undergraduates between 16-25 years old from two universities in south-west Nigeria (one control and one experimental). The intervention consisted of lectures on nutritional factors of stomach cancer one hour weekly for 8 weeks and a placebo lecture on HIV/AIDS stigmatization for the control group. A validated self-structured questionnaire was used to collect the data for the pretest and posttest. Demographic characteristics were analyzed with percentages; variables were analyzed using t-test and ANCOVA set at 95\% confidence interval. Nutrition education improved knowledge of nutrition in the participants $(\mathrm{p}<0.00)$. The experimental group displayed higher nutrition knowledge compared to control. Level of study affected participants' nutrition knowledge; students of lower level study performed better $(\mathrm{p}<0.00)$. Gender also affected participants' nutrition knowledge; females performed better than males $(\mathrm{p}<0.00)$. More nutrition education should be encouraged in school settings to improve knowledge of nutrition in order to prevent a possible dietary risk of stomach cancer and other chronic diseases.

Key words: Nutrition, Youth, Undergraduates, Cancer, Nigeria 


\section{INTRODUCTION}

Cancer remains an important factor in the global burden of disease [1]. The disease arises principally as a consequence of individuals' exposure to carcinogenic agents from what they inhale, drink and eat, or are exposed to in their personal work environment [2]. Previous reports on the effect of diet on cancer have stated that the cancer rates may increase by $50 \%$ up to 15 million new cases by 2020 worldwide and the report has advised that prompt action on cancer prevention should be considered to reduce morbidity and mortality everywhere in the world [3]. It also observed that diet is one of the three factors (others being smoking and infections), if managed properly, that can prevent one third of cancers as well as cure a second third of cancers [3].

Stomach cancer is one of the common cancers of the alimentary (digestive) tract worldwide [4]. Coren [5] also observed that cancers of the liver, stomach and oesophagus were more common in the developing world than the developed countries and that they are linked to the consumption of preserved foods with preservative chemicals having carcinogenic properties. Such foods include smoked or salted. He further noted that the most lethal cancers were prominently those of lung, stomach and liver, and these are vital organs for body performance. Nutritional knowledge has been identified as an important factor for adequate nutrition which enhances host resistance to chronic diseases and many studies have pointed out the usefulness of knowledge of nutrition in the prevention of cancer, especially diet related cancers amongst which a major one is stomach cancer [6-9]. Therefore, Health education which embraces nutrition education is considered one of the ways of achieving health related awareness by providing information on disease prevention [10-11].

In Nigeria, a recent study reported that upper gastro-intestinal diseases including stomach cancer has become relatively higher than in the past [12]. The report specifically pointed out that one hundred and two (11.6\%) patients out of eight hundred and eighty-two (882) patients who presented with upper gastro-intestinal diseases through upper gastro-intestinal endoscopy (UGIE) at Obafemi Awolowo Teaching Hospital, Ile-Ife had stomach cancer. However, there was no particular reason given for this relative increase. Oluwasola and Ogunbiyi [13] had earlier pointed out the dearth of data about cancer of the stomach in Nigeria and recommended that control measures be introduced for its prevention despite the apparently low incidence rates recorded, probably to keep it in check.

Stomach cancer has been strongly associated with high intake of salt, consumption of barbecued foods, red or over processed meat, mouldy food, low intake of fresh fruits, vegetables, fibre; high intake of dense calorie foods (doughnut, sausage, meat pie), excessive intake of alcohol, obesity as well as helicobacter pylori infection which can be contacted through contaminated water [14-15]. Almost all of these aforementioned dietary factors have been observed to be present in "junk" foods, which the undergraduates (young adults) are accustomed to. However, this may be changed by proper nutrition (health) related education [16-18]. The "junk" food consumed by most youth are calorie dense, a factor that causes release of Reactive Oxygen Specie 
(ROS) (free radicals) which are cancer promoting; these improper eating habits may predispose the consumers to diet related cancers with stomach cancer being the most prominent among such cancers [19-21 - 27].

It is perceived that these poor eating habits arise from lack of knowledge of the health consequences of their eating habits coupled with inadequate nutrition knowledge that can prevent and keep them away from stomach cancer and other chronic diseases. Therefore, if nutrition education is not put in place among the youth in Nigeria, there may be an upsurge of stomach cancer and other chronic diseases in the nearest future. Nutrition education, being an integral component of health education may provide adequate information that may be helpful to the individual in improving healthy nutrition knowledge and helping to make informed choices concerning food consumption. Many studies have not reported and emphasized on the use of nutrition education in bridging the gap in nutrition knowledge among the youth in Nigeria. This study, therefore, examined the effect of nutrition education on nutrition knowledge as a preventive measure against a possible rise in the incidence of stomach cancer among undergraduates in south-west Nigeria.

\section{MATERIALS AND METHODS}

\section{Study design and Location}

The study was a quasi-experimental design of the pretest and posttest method conducted in Obafemi Awolowo University, Ile-Ife and University of Ibadan, Ibadan in Osun and Oyo States, respectively in the south-west of Nigeria. The two universities are categorized as first generation universities. University of Ibadan is the first university in Nigeria and was founded in 1948; Obafemi Awolowo is also one of the oldest in Nigeria and was founded in 1962. Obafemi Awolowo University was selected as the experimental group and the University of Ibadan as the control group.

\section{Study Population and Sampling Procedure}

The study population comprised all undergraduates in Obafemi Awolowo University and University of Ibadan that are between 16 and 25 years of age. Four hundred and thirty-six participants, 259 (males and females) which is 1.5\% of the entire population in the experimental group and 177 (males and females) which is $1.5 \%$ of the entire population in the control group were randomly selected for the study. Two universities were selected from the three first generation universities in south-west Nigeria using simple random sampling with replacement method. The two universities were further randomly placed in experimental and control groups. The faculties in each selected university were stratified into two, namely: arts and science. Using simple random sampling with replacement, 50\% of faculties in each stratum were selected. Then, $25 \%$ of the departments in the selected faculties were selected using simple random technique. The participants in each of the selected department were again divided into three strata according to their levels of study namely: 100-200 level, 300-400 level and 500-600 level.

Using systematic sampling procedure, $5 \%$ of the participants were selected from each stratum in each department for the study. Males and females aged between 16 and 25

Published by African Scholarly Science Communications Trust
Josem Trust Place, Bunyala Road, Upper Hill, Nairobi
P.O. Box 29086-00625 Tel: +254-20-2351785 Fax: +254-20-4444030, Nairobi, KENYA
Email: oniango@iconnect.co.ke OR info@ajfand.net www.ajfand.net


years participated in the study. With this procedure, two hundred and fifty-nine (259) participants were selected from the experimental group and one hundred and seventyseven (177) participants were selected from the control group; this made a total of four hundred and thirty-six (436) participants from both universities. However, three hundred and ninety-eight (398) participants completed the study with $8.7 \%$ attrition rate which may be due to some students having tight lecture schedules.

\section{Data Collection}

The instruments for collecting data required for this study were in three steps. The first step of the experimental design was the development of focus group discussion (FGD) guide. The guide was used for the discussion which collected baseline information that revealed areas of attention that had to be addressed during the course of intervention. The focus group discussion was in four sessions in each university as follows: males: 100-300 level; 400-600 level; females: 100-300 level; 400-600 level. Each session comprised 8-11 participants that were selected using congruent purposive random sampling technique. The principal investigator was the moderator of the FGD, assisted by a secretary and a timekeeper/observer. Each discussion session took place in the students' halls of residence for a duration of between 45-60 minutes. All the discussion sessions were tape-recorded and later transcribed.

The second step of the experimental design was the development of validated structured questionnaire on the nutrition knowledge of the participants in relation to stomach cancer. The questionnaire was self-developed and the content of the questionnaire was guided by the study's specific objective and review of literature on nutrition education and knowledge. The psychometric properties of the questionnaire were determined by carrying out item analysis of each question and Cronbach Alpha was used to determine the reliability coefficient and this yielded 0.79 . The questionnaire was organised into two sections.

Section A elicited information on the sociodemographic attributes of the participants (gender, age); this section consisted of four (4) items.

Section B elicited information on nutrition knowledge relating to stomach cancer. It consisted of nineteen (19) items. Closed ended questions (dichotomous) with "Yes" or "No" options, multichotomous options.

Multiple Choice Questions (MCQ) and open ended questions were used. These variables testing nutrition knowledge were given different scores ranging from 0-4 as necessary since the questions were dichotomous and multichotomous. A nutrition scoring scale was designed that was used to allot scores to the participants both before and after the nutrition education intervention; a maximum of sixty marks (60 marks) were allotted.

Responses were graded as follows: 0-30=poor, 31-40=fair, 41-50=good, 51-60=very good. The questionnaire was used for the pretest and posttest of the participants. Before teaching the experimental group, the questionnaire was administered and same was administered immediately after the intervention and repeated after eight weeks to 
confirm the effect of the intervention. The control group also had the same questionnaire as that of the experimental group administered before and after giving them a placebo treatment on HIV/AIDS stigmatization. Ten research assistants who were undergraduates were used for the study and on-the-spot collection of the questionnaires were ensured. The research was carried out between November, 2009 and March 2010.

The third step of the experimental design was the development of the intervention package guide and content which was used for the teaching of the experimental group on nutritional factors that may predispose to stomach cancer and how it would be prevented. The intervention package consisted of brief anatomy of the stomach, general causes of cancer and specific causes of stomach cancer, good eating habits (nutrition facts, meal skipping), fruit and vegetable consumption, diet and cancer, healthy feeding and unhealthy feeding. The intervention programme lasted eight (8) weeks.

\section{Data Analysis and Statistical Methods}

Data analysis was carried out using the Statistical Package for Social Sciences (SPSS) for Windows version 15.0. Frequency counts and percentages were used to describe the demographic characteristics of the participants. Analysis of covariance (ANCOVA) was used to determine the effect of nutrition education on the nutrition knowledge of the participants in the control and experimental groups and also to determine the effect of level of study on the nutrition knowledge. Independent t-test was used to determine the effect of age and gender on the nutrition knowledge of the participants. The alpha level of acceptance of all the variables tested was fixed at $95 \%$ confidence limit.

\section{Ethical Consideration}

The research protocol was approved by the Ethics Committee of the Oyo State Ministry of Health Ibadan, Nigeria. A written consent was sought from the participants before their participation in the study.

\section{RESULTS}

The demographic characteristics of the participants are shown in table 1 . The total number of participants in the experimental group was 225 which represented $56.5 \%$ of the total participants, and the number of participants in the control group was 173 which represented $43.5 \%$ of the total participants. Thus, the total number of participants in the study was 398. The distribution of the participants by the level of study shows that 189 participants (68 in the control group and 121 in the experimental group) representing $47.5 \%$ of the total participants were in the group of 100-200 level, 178 participants (80 in the control group and 98 in the experimental group) representing $44.7 \%$ of the total participants were in the group of 300-400 level, while 31 participants (25 in the control group and 6 in the experimental group) representing $7.8 \%$ were in the group of 500-600 level. The gender distribution of the participants shows that the total number of male participants was 203 representing $51.0 \%$ of the total participants and the female participants were 195 representing $49.0 \%$ of the total 
participants. The age distribution of the participants shows that 127 (56 in the control group and 71 in the experimental group) representing 31.9\% of the participants were between 16 and 20 years of age, while 271 (117 in the control group 154 in the experimental group) representing 68.1\% of the participants were between 21 and 25 years of age.

Tables 2.1 and 2.2 present the percentage grading of the nutrition knowledge in the participants. In the experimental group, $92.5 \%$ of the participants were rated poor and fair before the intervention, but after the intervention, 36.9\% were rated poor and fair. In the control group $94.2 \%$ of the participants were rated poor and fair before the intervention and after the intervention, 94.2\% were still rated poor and fair.

The result of examining the effect of training on the knowledge of nutrition was shown on tables 3.1, $3.2 \&$ 3.3. The result presented on table 3.1 shows that the experimental group had a mean gain of 13.81; while the control group had a mean gain of 3.08. Table 3.2 shows that there is a significant difference in the knowledge of nutrition of the participants after nutrition education intervention $\left(F_{(2.395)}=88.472\right.$, $\mathrm{P}=0.000$ ). In the further analysis to know the direction of the difference, the Multiple Classification Analysis result in table 3.3 shows that the experimental group contributed the mean score of 39.22 while the control group had a mean score of 29.32, respectively (calculated from the grand mean and unadjusted variation). The coefficient of determination $\mathrm{R}^{2}=.184$ implies that $18.4 \%$ of the knowledge gain was accounted for by the intervention. This further implies that the nutrition education given was effective.

The effect of the level of study on the knowledge of nutrition is shown in tables $4.1 \&$ 4.2; the result in table 4.1 shows that there was a significant difference in the level of study on knowledge of nutrition after the intervention $\left(\mathrm{F}_{(3,394)}=5.735, \mathrm{P}=0.00\right)$. Further analysis on the contributions of the levels of study (table 4.2), shows that 100200 level contributed the mean score of 36.71; 300-400 level contributed mean score of 33.79 and 500-600 level contributed the mean score of 30.48 (calculated from the grand mean and unadjusted variation). The coefficient of determination $R^{2}=.029$. Therefore, $2.9 \%$ of the difference was accounted for by the intervention. This result also suggests the effectiveness of the nutrition education intervention.

The effect of gender and age on nutrition knowledge was also determined. The result is presented in table 5 . Before the intervention, gender significantly affected the nutrition knowledge of the participants (Crit- $\mathrm{t}=1.96$, Cal. $\mathrm{t}=2.37, \mathrm{df}=396, \mathrm{P}=0.02$ ). Also, after the intervention, gender significantly affected the knowledge of the participants (Crit-t $=1.96$, Cal.t $=3.86, \mathrm{df}=396, \mathrm{P}=0.00$ ). The two age groups did not significantly affect the knowledge of nutrition of the participants both before and after the intervention. The result before the intervention was Crit- $t=1.96$, Cal.t $=.59$, $\mathrm{df}=396, \mathrm{P}=0.56$ and the result after the intervention was Crit-t $=1.96$, Cal.t $=.66$, df $=396, \mathrm{P}=0.51$. 


\section{DISCUSSION}

The role of nutrition education has been attributed to that of improving nutrition knowledge, dietary concept and behaviour in the community [21-22; 28-30]. This intervention programme, therefore, targeted the use of nutrition education to reduce poor nutrition knowledge which may predispose undergraduates to stomach cancer in south-west Nigeria. In the initial scoring done, the experimental group performed much better than the control group after the nutrition education intervention. The other analyses in this study show that there is a higher score in the mean value of the experimental group in the knowledge of nutrition compared to that of the control group after the intervention. The mean difference after intervention further shows that the experimental group had a mean gain of 13.81, while the control group had a mean gain of 3.08. It may be inferred that the nutrition education intervention training programme may have accounted for the $18.4 \%$ of the nutrition knowledge gained as indicated in the multiple classification analysis result.

It does appear that nutrition education improved the knowledge of the participants in the experimental group who had a lower mean score before the intervention compared to the control group. The experimental group is noticed to have performed remarkably better than the control group, going by the fact that the control group scored a higher mean than the experimental group before the intervention. It is also observable that before the nutrition education training intervention, there was no significant difference in knowledge of nutrition on stomach cancer but after the intervention, there was a significant difference in knowledge of nutrition on stomach cancer. Also, in the focus group discussion carried out before the intervention programme, the participants did not exhibit adequate knowledge of nutrition in relation to stomach cancer. From their responses, the participants placed more importance on calorie and fat aspects of the diet rather than quality and protective nutrients of the food consumed. Clearly this notion is detrimental to health and predisposes individuals to chronic disease amongst which is stomach cancer [18-19, 21-23]. Significantly put together, these results suggest that the nutrition education intervention has had a marked impact on the participants and that learning has taken place.

This remarkable improvement in knowledge after the nutrition education intervention may be considered a pivotal factor that may help to improve behaviour and attitude. It is assumed from this result that most of the gap in knowledge of nutrition predisposing to stomach cancer has been corrected by the nutrition education given. This assertion is in line with the observation in previous studies where high levels of knowledge have been associated with healthy changes in beliefs and food consumption [18-24]. Knowledge, even when it does not fully change behaviour, creates awareness so that the individual is not ignorant and can make informed decisions.

In examining the effect of the level of study on the participants, the level of study had a significant effect on their knowledge of nutrition. The multiple classification analysis shows that students in 100-200 level contributed the highest mean score, followed by students in 300-400 level and 500-600 level, respectively. The coefficient 
of determination $\mathrm{R}^{2}$ is 0.029 . The finding in this result also implies that the junior students performed better than the senior students, in terms of improved knowledge. Again, this is a surprising result as one would have expected a better synthesis and application of knowledge given from the senior students because they are relatively more mature. This outcome may be due to lack of interest on the part of the senior students, and it may also imply that the younger ones are easier to teach and more amenable to correction than the senior students. This result suggests that younger students are easier to change than older ones. In previous reports [25-26] lower grade students had better eating habits than students in higher grades.

In examining the effect of gender on the nutrition knowledge before and after the intervention programme, gender was significant both in the pretest and posttest. Surprisingly, the male group contributed a higher mean score than the female group in the pretest. This implies that the males in this study had a better understanding of how nutrition may predispose to stomach cancer than their female counterparts before the intervention programme. After the intervention, gender was again significant; the females now contributed a better mean score than their male counterparts. This also implies that the female group has now become more knowledgeable as a result of the nutrition education intervention. It can, therefore, be further inferred that nutrition education is a potent tool to bridge the gap in knowledge. This assertion has been previously reported $[10-11,19]$.

In examining the effect of the two age groups on the nutrition knowledge of the participants before and after the intervention, there was no significant difference. The finding in this study appears to be at variance with the reports from previous studies where younger adolescents had better healthy eating habits than older adolescents [25-26]. It may be assumed that the age limit of the participants in this study is probably not wide enough to bring about a significant difference.

\section{CONCLUSION}

Data from this study revealed that nutrition education intervention through training has a significant effect on nutrition knowledge that may be preventive against stomach cancer. Gender and educational level significantly affect nutrition knowledge where age does not affect nutrition knowledge. School environment provides a good setting for health promotion programmes including nutrition information. Nutrition education intervention is a reliable measure and should be encouraged to increase nutrition knowledge as it appears an inexpensive means of preventing stomach cancer, which is deadly and very expensive to treat when established. It will also prevent other diet related cancers and chronic diseases.

\section{CONTRIBUTORS}

Dr Gloria O. Anetor was the principal investigator for the study and took the lead in planning the study report here. Prof. Benjamin O Ogundele and Dr Emmanuel O Oyewole contributed intervention expertise and contributed to the analytic plan. Dr Gloria Anetor and Dr Emmanuel Oyewole edited the discussion section. All contributors are guarantors for the integrity of the article as a whole. 


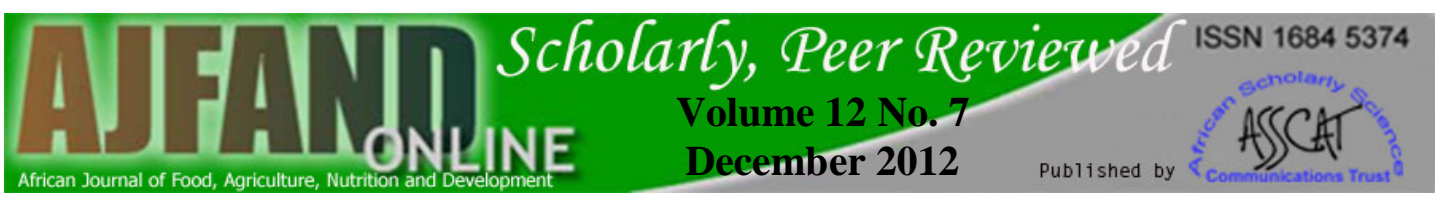

\section{ACKNOWLEDGEMENTS}

This study was funded by the corresponding author. The authors are very much indebted to the advice and support of Prof John Anetor of the College of Medicine, University of Ibadan, Dr Abiodun O Ajose of the College of Health Sciences Obafemi Awolowo University Ile-Ife, the analyst Mr. Ayo Odewunmi, the research assistants in Obafemi Awolowo University and University of Ibadan and all the students from both Universities who participated in this study. 
Table 1: Demographic characteristics of participants

\begin{tabular}{|c|c|c|c|}
\hline Characteristics & Frequency & Percentage & Total \\
\hline \multicolumn{4}{|l|}{ Participants } \\
\hline Experimental & 225 & $56.5 \%$ & \multirow[b]{2}{*}{398 (100\%) } \\
\hline Control & 173 & $43.5 \%$ & \\
\hline \multicolumn{4}{|l|}{ Gender } \\
\hline \multicolumn{4}{|l|}{ Male } \\
\hline 1. Experimental & 97 & $24.4 \%$ & \multirow{2}{*}{203 (51\%) } \\
\hline 2. Control & 106 & $26.6 \%$ & \\
\hline \multicolumn{4}{|l|}{ Female } \\
\hline 1. Experimental & 128 & $32.2 \%$ & \multirow{2}{*}{195 (49\%) } \\
\hline 2. Control & 67 & $16.8 \%$ & \\
\hline \multicolumn{4}{|l|}{ Age range in years } \\
\hline \multicolumn{4}{|l|}{$16-20$ years } \\
\hline 1. Experimental & 71 & $17.8 \%$ & \multirow{2}{*}{127 (31.9\%) } \\
\hline 2. Control & 56 & $14.1 \%$ & \\
\hline \multicolumn{4}{|l|}{$21-25$ years } \\
\hline 1. Experimental & 154 & $38.7 \%$ & \multirow{2}{*}{271 (68.1) } \\
\hline 2. Control & 117 & $29.4 \%$ & \\
\hline \multicolumn{4}{|l|}{ Level of study } \\
\hline \multicolumn{4}{|l|}{$100-200$} \\
\hline 1. Experimental & 121 & $30.4 \%$ & \multirow{2}{*}{189 (47.5) } \\
\hline 2. 2. Control & 68 & $17.1 \%$ & \\
\hline \multicolumn{4}{|l|}{$300-400$} \\
\hline 1. Experimental & 98 & $24.6 \%$ & \multirow{2}{*}{178 (44.7\%) } \\
\hline 2. Control & 80 & $20.1 \%$ & \\
\hline \multicolumn{4}{|l|}{$500-600$} \\
\hline 1. Experimental & 6 & $1.5 \%$ & \\
\hline 2. Control & 25 & $6.3 \%$ & $31(7.8 \%)$ \\
\hline
\end{tabular}




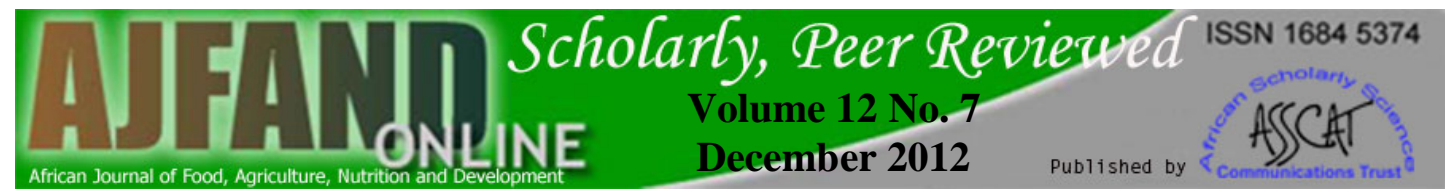

Table 2.1: Control group's percentage grading on knowledge of nutrition

\begin{tabular}{|l|c|l|l|l|}
\hline \multicolumn{2}{|l|}{ PRETEST } & POSTTEST & \\
\hline Range of scores & Frequency & Percentage & Frequency & Percentage \\
\hline $0-30$ & 111 & $64.2 \%$ & 104 & $60.1 \%$ \\
\hline $31-40$ & 52 & $30.0 \%$ & 59 & $34.1 \%$ \\
\hline $41-50$ & 10 & $5.6 \%$ & 10 & $5.6 \%$ \\
\hline $\begin{array}{l}51-60 \\
\text { Total No of } \\
\text { participants }\end{array}$ & 173 & $0 \%$ & 0 & $0 \%$ \\
\hline
\end{tabular}

Grading: 0-30=Poor; 31-40=Fair; 41-50=Good; 51-60=Very good 


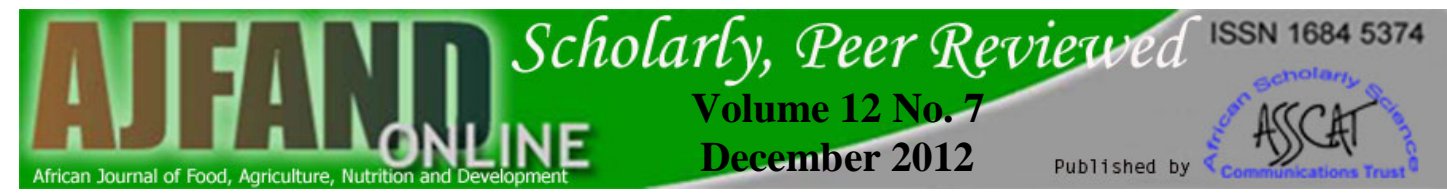

Table 2.2: Experimental group's percentage grading on knowledge of nutrition

\begin{tabular}{|c|c|c|c|c|}
\hline & PRETEST & & POSTTEST & \\
\hline $\begin{array}{l}\text { Range of } \\
\text { scores }\end{array}$ & Frequency & Percentage & Frequency & Percentage \\
\hline $0-30$ & 125 & $55.6 \%$ & 5 & $2.2 \%$ \\
\hline $31-40$ & 83 & $36.9 \%$ & 78 & $34.7 \%$ \\
\hline $41-50$ & 17 & $7.6 \%$ & 126 & $56.0 \%$ \\
\hline $51-60$ & 0 & $0 \%$ & 16 & $7.1 \%$ \\
\hline $\begin{array}{l}\text { Total No of } \\
\text { participants }\end{array}$ & 225 & & 225 & \\
\hline
\end{tabular}

Grading: 0-30=Poor; 31-40=Fair; 41-50=Good; 51-60=Very good 


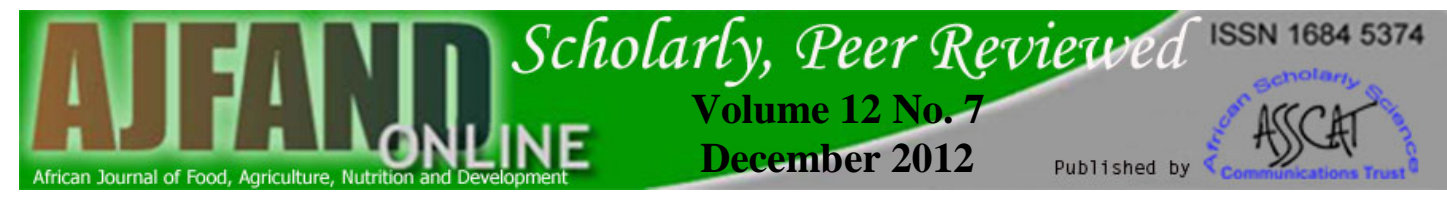

Table 3.1: Descriptive analysis of nutrition knowledge of the participants

\begin{tabular}{|l|l|l|l|l|l|l|l|}
\hline & \multicolumn{3}{|l|}{ Pretest } & Posttest & & \\
\hline Group & N & Mean & SD & Mean & SD & Mean difference & p-value \\
\hline Experimental & 225 & 25.41 & 6.75 & 39.22 & 12.45 & 13.81 & 0.00 \\
\hline Control & 173 & 26.24 & 8.76 & 29.32 & 7.11 & 3.08 & 0.20 \\
\hline
\end{tabular}

Table 3.2: Analysis of the knowledge of nutrition of the participants

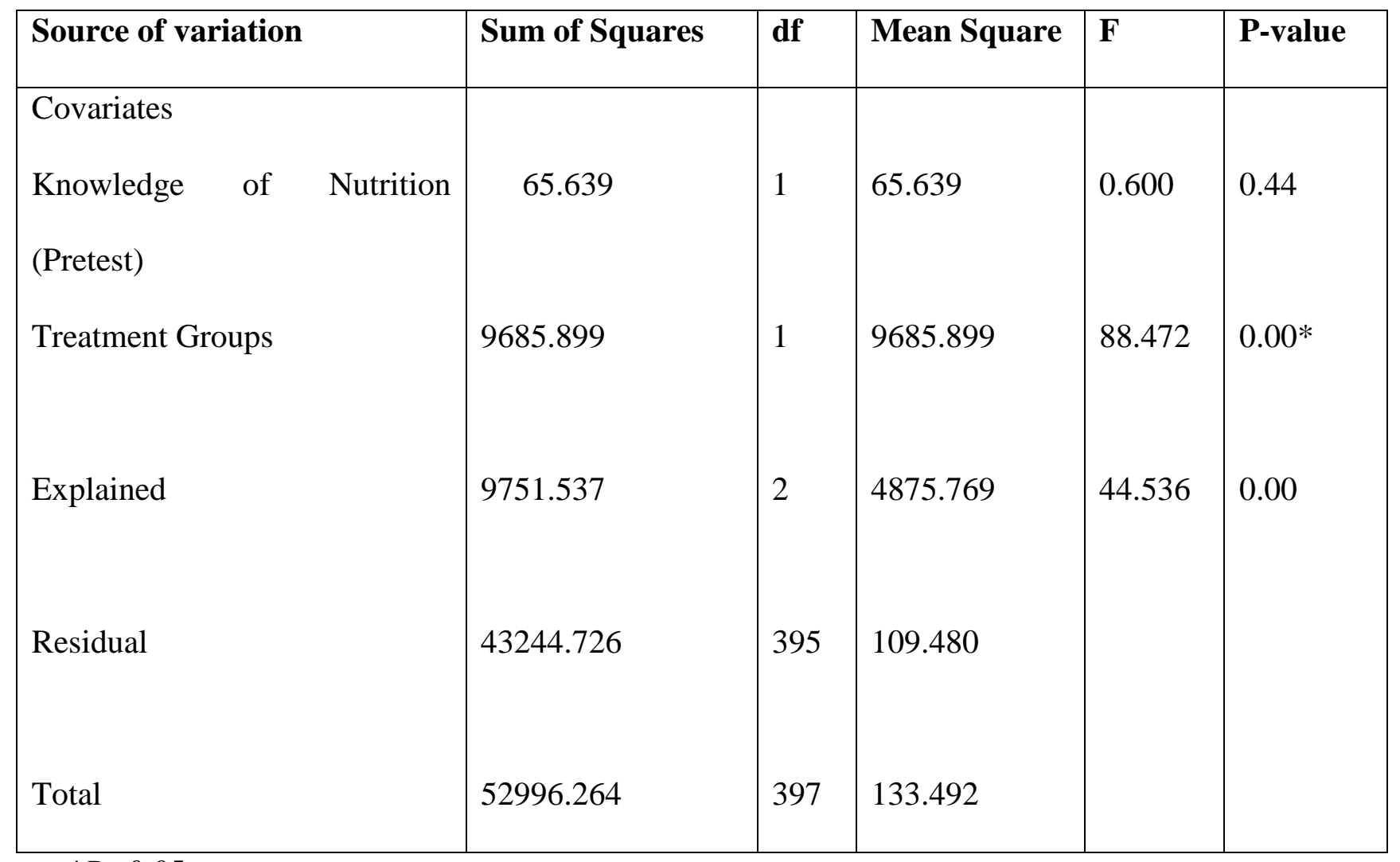

$* P<0.05$ 


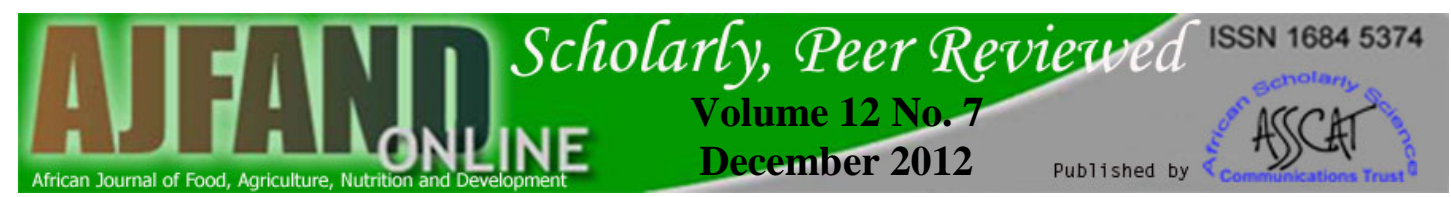

Table 3.3: The direction of the knowledge of nutrition in the participants

Grand Mean = 34.92

\begin{tabular}{|l|l|l|l|l|l|}
\hline $\begin{array}{l}\text { Variable + } \\
\text { Category }\end{array}$ & $\mathbf{N}$ & $\begin{array}{l}\text { Unadjusted } \\
\text { variation }\end{array}$ & Eta & $\begin{array}{l}\text { Adjusted for independent + } \\
\text { covariates deviation }\end{array}$ & Beta \\
\hline Experiment Group & 225 & 4.30 & & 4.30 & 0.43 \\
Control Group & 173 & -5.59 & 0.43 & -5.63 & 0.184 \\
\hline $\begin{array}{l}\text { Multiple R-squared } \\
\text { Multiple R }\end{array}$ & & & & 0.429 \\
\hline
\end{tabular}

Multiple Classification Analysis

Table 4.1: Effect of the level of study on the knowledge of nutrition

\begin{tabular}{|l|l|r|l|l|l|}
\hline Source of variation & $\begin{array}{l}\text { Sum of } \\
\text { Squares }\end{array}$ & df & $\begin{array}{l}\text { Mean } \\
\text { Square }\end{array}$ & F & P- value \\
Covariates (Pretest knowledge of & 65.639 & 1 & 65.639 & 0.503 & 0.48 \\
Mutrition) & 1497.289 & 2 & 748.645 & 5.735 & $0.00^{*}$ \\
Explained & 1562.928 & 3 & 520.976 & 3.991 & 0.01 \\
Residual & 51433.336 & 394 & 130.541 & & \\
Total & 52996.264 & 397 & 133.492 & & \\
\hline
\end{tabular}

$* P<0.05$ 


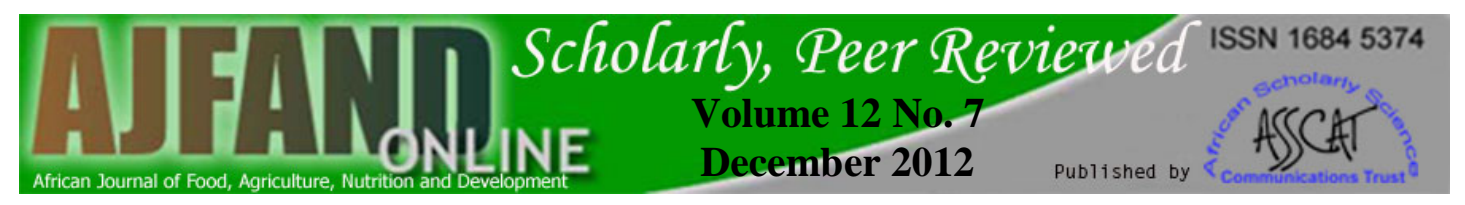

Table 4.2: The direction of the level of study on knowledge of nutrition

Grand Mean $=34.92$

\begin{tabular}{|c|l|l|l|l|l|}
\hline Variable + Category & $\mathbf{N}$ & $\begin{array}{l}\text { Unadjusted } \\
\text { variation }\end{array}$ & Eta & $\begin{array}{l}\text { Adjusted for independent + } \\
\text { covariates deviation }\end{array}$ & Beta \\
\hline Level: $100-200$ & 189 & 1.79 & .17 & 1.81 & .17 \\
$300-400$ & 178 & -1.13 & & -1.12 & \\
$500-600$ & 31 & -4.43 & & -4.62 & \\
\hline
\end{tabular}

Multiple Classification Analysis 


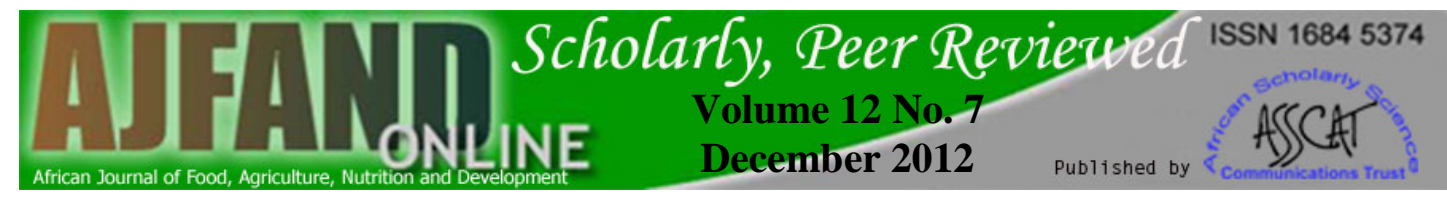

Table 5: Analysis of Knowledge of Nutrition by Gender and Age

\begin{tabular}{|c|c|c|c|c|c|c|c|c|}
\hline & Variables & & \multicolumn{3}{|c|}{ Pretest } & \multicolumn{3}{|c|}{ Posttest } \\
\hline & Gender & $\mathbf{N}$ & Mean & t-value & P-value & Mean & t-value & P-value \\
\hline \multirow{2}{*}{$\begin{array}{l}\text { Knowledge } \\
\text { of } \\
\text { Nutrition }\end{array}$} & Male & 203 & 26.66 & 2.37 & 0.02 & 32.76 & 3.86 & $0.00 *$ \\
\hline & Female & 195 & 24.85 & & & 37.16 & & \\
\hline \multirow{3}{*}{$\begin{array}{l}\text { Knowledge } \\
\text { of } \\
\text { Nutrition }\end{array}$} & Age ( years) & & & & & & & \\
\hline & $16-20$ & 127 & 25.44 & 0.59 & 0.56 & 34.36 & 0.66 & 0.51 \\
\hline & $21-25$ & 271 & 25.93 & & & 35.18 & & \\
\hline
\end{tabular}

$* P<0.05$ 


\section{REFERENCES}

1. World Health Organization (WHO). WHO/Cancer: Diet and physical activity’s impact. http://www.who.int/entity/dietphysicalactivity/en. 2007. Accessed December 5, 2008.

2. National Cancer Institute (NCI). What you need to know about stomach cancer. http://www.cancer.gov/cancertopics/wyntk/stomach. Accessed December 5, 2007.

3. World Health Organization (WHO). Global cancer rates could increase by $50 \%$ to 15 million by 2020 . http://www.who.int/mediacentre/news/releases/2003/Pr27/en. Accessed October 3, 2007.

4. Gunderson LL, Donohue JH and SR Alberts Cancer of the stomach. In: Abellof MD, Armitage JO, Niederhuber JE, Kastan MB and McKena WG (Eds). Clin Oncology. $3^{\text {rd }}$ ed. Philadelphia: Elsevier Churchill Livingstone. 2004; 79:380-415.

5. Coren $\mathbf{M}$ Cancer no longer rare in poor countries. www.cnn.com/2005/Health/03/09/cancer.study/index.html. Accessed February 10, 2009.

6. Schaller C and EL James The nutritional knowledge of Australian Nurses. Nurse Educ Today. 2005; 25:405-412.

7. Özçelik AO, Sürücüoglu MS and LS Akan Survey on the nutrition knowledge level of Turkish Physicians: Ankara as a sample. Pakistan J Nutri. 2007; 6(60): 538-542.

8. Prell HC, Berg MC, Jonsson LM and L Lissner A school-based intervention to promote dietary change. J. Adoles Health 2005; 36:529 -534.

9. Anderson AS, Porteous LE, Foster G, Higgins C, Stead M, Hetherington M, Ha MA and AJ Adamson Impact of school-based nutrition education intervention on dietary intake and cognitive and attitudinal variables relating to fruits and vegetables. J. Pub Health Nutri 2004; 8 (6): 650656.

10. Charny M and PA Lewis Does health knowledge affect eating habits? Health Educ. J. 1987; 46(4): 172-176.

11. Ajala JA Health education in wellness and sickness: This day, this age. Ibadan: May Best Publications; 2005.

12 Agbakwuru EA, Fatusi AO, Ndububa DA, Alatise OI, Arigbabu OA and DO Akinola Pattern and validity of clinical diagnosis of upper gastrointestinal diseases in South-Western Nigeria. Afr. J. Health Sci. 2006; 6(2):98-103. 
13. Oluwasola AO and JO Ogunbiyi Gastric cancer: aetiological, clinicopathological and management patterns in Nigeria. Nig. J. Med. 2003; 12(4):177-186.

14. Ehealth MD Who Gets Stomach Cancer? www.ehealthMD.com Accessed December 12, 2008.

15. Crew KD and AI Neugut Epidemiology of cancer. World J. Gastroent. 2006; 12(3):354-362.

16. Popkin BM The nutrition transition and its health implications in lower income countries. Public Health Nutri. 1998; 1: 5-21.

17. Papadaki A and JA Scott The impact on eating habits of temporary translocation from a Mediterranean to a Northern European environment. European J. Clin. Nutri. 2002; 56(5): 455 - 467.

18. Saad L Nearly one in five teens is overweight. Gallup News Service. H: Nearly One in Five Is Overweight.mht. Accessed April 26, 2009.

19. Rodgers $\mathbf{E}$ and $\mathbf{C}$ Wendt Factors that influence eating behaviour. BC Health Guide http://sh-print.healthwise.net/webprint/webprintMgr.aspx?c=moh2005. Accessed January 3, 2007.

20. Ledikwe JH, Ello-Martin JA and BJ Rolls Fast foods, energy density and obesity: a possible mechanistic link. Obesity Rev. 2005; 4:187-194.

21. Turconi G, Guarcello M, Maccarini L, Cignoli F, Setti S, Bazzano R and C Roggi Eating habits and behaviours, physical activity, nutritional and food safety knowledge and beliefs in an adolescent Italian population. J. Am Coll Nutri 2008; 27 (1):31-43.

22. Delisle HF, Vioque $\mathbf{J}$ and A Gil Dietary patterns and quality in west-Africa immigrants in Madrid. http://www.nutritionj.com/content /8/1/3. Accessed April 26, 2009.

23. Dibsdall LA, Lambert N, Bobbin RF and LJ Frewer Low-income consumers' attitudes and behaviour towards access, availability and motivation to eat fruit and vegetables. Public Health Nutri. 2003; 6 (2):159-68.

24. Thiele S, Mensink GBM and R Beitz Determinants of diet quality. Public Health Nutri. 2003; 7 (1):29-37.

25. Westenhoefer $\mathbf{J}$ Age and gender dependent profile of food choice. Forum Nutri. 2005; 57:44- 51.

26. Driskell J, Kim Y-N and K Goebel Few differences found in the typical eating and physical activity habits of lower-level and upper-level university students. J Am Diet Assoc. 2005; 105:798-801. 
27. Ajmera $\mathbf{R}$ The effects of poor nutrition on your health. http://www.livestron.com/article/31172 - effects-poor-nutrition-health. Accessed March 30, 2011.

28. Sun WY, Sangweni B, Chen $\mathbf{J}$ and S Cheung Effects of a community-based nutrition education program on the dietary behavior of Chinese-American college students. Health Promotion International. 1999; 14: 241-249.

29. Packman $\mathbf{J}$ and SFL Kirk The relationship between nutritional knowledge, attitudes and dietary fat consumption in male students. Human Nutri and Diet. 2000; 13:390-395.

30. Watson LC, Kwon J, Nichols D and M Rew Evaluation of the nutrition knowledge, attitudes, and food consumption behaviors of high school students before and after completion of a nutrition course. Family and Consumer Science Res. 2009; 37:523-524. 